\title{
Pathways to Commercialisation for Brown Coal Fly Ash-Based Geopolymer Concrete in Australia
}

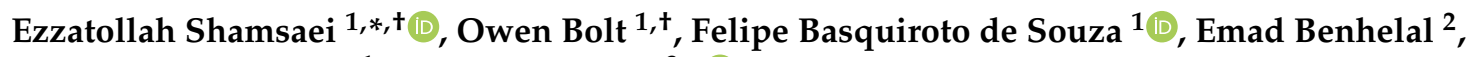 \\ Kwesi Sagoe-Crentsil ${ }^{1}$ and Jay Sanjayan ${ }^{3, *}$ (D) \\ 1 Department of Civil Engineering, Monash University, Clayton, VIC 3800, Australia; \\ ogbol1@student.monash.edu (O.B.); felipe.basquiroto@monash.edu (F.B.d.S.); \\ kwesi.sagoe-crentsil@monash.edu (K.S.-C.) \\ 2 The University of Newcastle Research Associate (TUNRA), The University of Newcastle, \\ Callaghan, NSW 2308, Australia; emad.benhelal@uon.edu.au \\ 3 Center for Smart Infrastructure and Digital Construction, Swinburne University of Technology, \\ Hawthorn, VIC 3122, Australia \\ * Correspondence: ezzatollah.shamsaei@monash.edu (E.S.); jsanjayan@swin.edu.au (J.S.) \\ + Co-First authors.
}

Citation: Shamsaei, E.; Bolt, O.; Basquiroto de Souza, F.; Benhelal, E.; Sagoe-Crentsil, K.; Sanjayan, J. Pathways to Commercialisation for Brown Coal Fly Ash-Based Geopolymer Concrete in Australia. Sustainability 2021, 13, 4350. https:// doi.org/10.3390/su13084350

Academic Editor: Moncef L. Nehdi

Received: 11 March 2021

Accepted: 9 April 2021

Published: 14 April 2021

Publisher's Note: MDPI stays neutral with regard to jurisdictional claims in published maps and institutional affiliations.

Copyright: (c) 2021 by the authors. Licensee MDPI, Basel, Switzerland. This article is an open access article distributed under the terms and conditions of the Creative Commons Attribution (CC BY) license (https:/ / creativecommons.org/licenses/by/ $4.0 /)$.
Abstract: Utilising geopolymer as a construction material has gained institutional and commercial interest over the past decade, due to its favourable emissions profile as an alternative to carbonintensive Ordinary Portland Cement-based concrete, which currently accounts for around $7 \%$ of global carbon emissions. While significant research has been performed into the material properties of geopolymer, the commercialisation of the technology is still in its infancy, and several key barriers require rectification to facilitate more widespread adoption. This article analyses the current state of geopolymer commercialisation, paying particular attention to its commercial application in Australia, and it suggests key research areas, in particular relating to the utilisation of abundant and cheap low-quality fly ash sources such as brown coal-based fly ash, to promote its adoption and build on the momentum gained from the small scale in situ pours of geopolymer concrete. Our analysis indicated that in addition to the barriers relating to material properties, economic, social, and regulatory issues also require further inquiry. Our review also indicated that it is critical to update and improve economic analysis of geopolymer utilisation to forecast future costs of both geopolymer and concrete mixes, which are especially critical in determining any potential financial incentives for the construction industry. Moreover, it is essential to study the social attitudes affecting future geopolymer consumption and to update the regulatory standards governing geopolymer utilisation in Australia, such as the initial steps undertaken by the Low Carbon Living Cooperative Research Centre. Based on this review, it is suggested that solving these key issues would help proliferate geopolymer technology and further aid efforts to create a more environmentally sustainable construction industry.

Keywords: geopolymer concrete; commercialisation; material properties; economic factors; social attitudes; regulatory environment

\section{Introduction}

Industrial processes are one of the main sources of greenhouse gas (GHG) emissions, burning significant quantities of fossil fuels and producing huge amounts of mass in situ GHGs in their operations. The cement industry is a major source of GHGs, being responsible for $26 \%$ of industrial and $7 \%$ of global carbon emissions [1]. Cement substitution in concrete with alternative materials is a promising approach to reduce carbon emissions produced by the cement and concrete industry. Various materials with pozzolanic property can replace cement in concrete, among them geopolymers, a material first coined by Davidovits [2].

The term geopolymer refers to the formation of a structural material made through the dissolution and polymerisation of source material high in reactive silica and alumina 
(Figure 1) [2]. These materials are commonly precipitated through highly alkaline activating solutions such as sodium/potassium hydroxides and silicates [3]. When combined with aggregates, a structural material with properties similar to concrete can be manufactured, with added advantages over carbon emissions-intensive construction materials such as Ordinary Portland Cement (OPC) [4]. That is because geopolymer binders can be produced exclusively of recycled waste materials such as fly ash, which is a by-product of coalfired power plants with associated environmental and health hazards in several countries due to the large waste stockpiles deposited into landfill [5]. Increasing the application of geopolymer, and specifically fly ash, could have significant environmental and societal benefits through a reduction in cement reliance and subsequent emissions savings, as geopolymer technology can produce 10-64\% less GHG emissions when compared to OPC concrete of the same strength $[4,6-8]$.

Australia is currently one of the international leaders in geopolymer innovation [9-11]. Research in Australian universities and institutes focusing on the strength and durability properties of the material has been ongoing since the turn of the millennium through studies undertaken by Van Jaarsveld [12] and Van Deventer [13]. Furthermore, the market presence of companies producing geopolymer indicates that Australia continues to be a global innovator in this field $[14,15]$. Nevertheless, despite the abundance of geopolymer research undertaken in Australia, there persists a significant underutilisation of fly ash, in particular, low-quality fly ash from sub-bituminous and brown coal, in the Australian market when compared to other developed and developing countries [16,17]. This poses a significant environmental issue when coupled with Australia's rising demand for concrete [18], as increased consumption of concrete without supplementary or substitutional use of geopolymer will further increase the carbon footprint of Australia's construction industry [19].

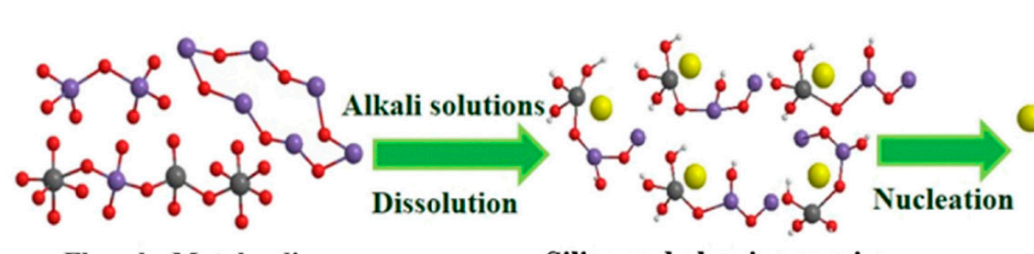

Fly ash; Metakaolin; Silica fume; Slag

Silica and alumina species

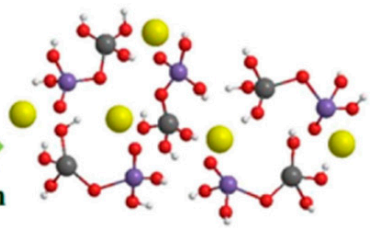

Aluminosilicate oligomers $(\mathrm{Si} / \mathrm{Al}=1)$

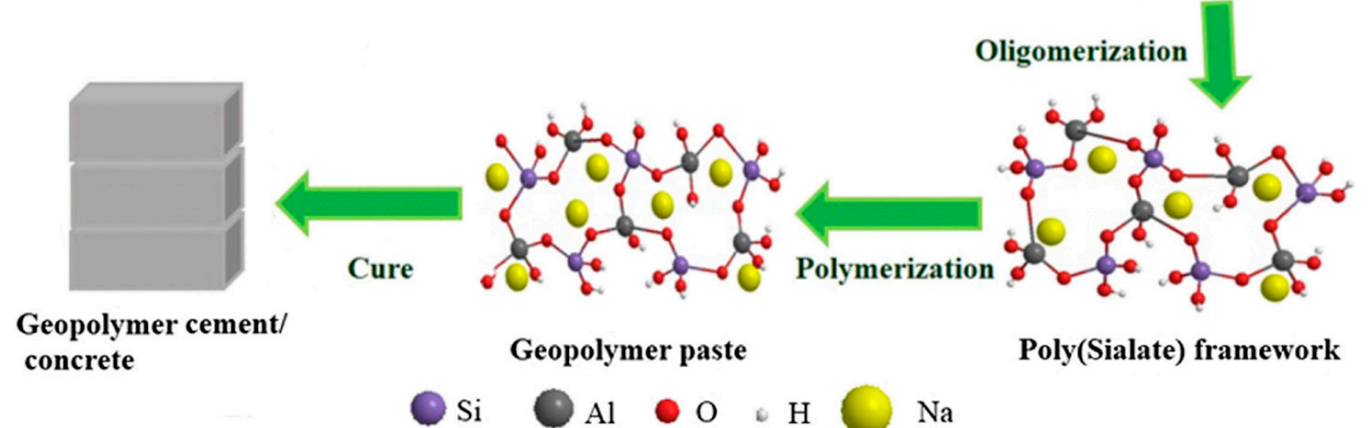

Figure 1. Geopolymerisation process for the fabrication of geopolymer cement/concrete. Different sources of siliceous and aluminous materials are used for the production of geopolymers, the most common including fly ash, metakaolin, silica fume, ground granulate blast slag, and other ashes such as volcanic and biomass ashes. Reprinted with permission from ref. [20]. Copyright 2016 Elsevier.

The commercialisation of the product is the key approach to increasing the utilisation of geopolymer. Nevertheless, there are several challenges for the adoption of geopolymers in the construction industry such as (1) the material properties (i.e., strength and durability), (2) economic factors, (3) social attitudes to the relatively unknown technology, and (4) the regulatory environment. These factors are interconnected and can pose significant barriers to widespread adoption. 
This article aims to provide a perspective of the current body of research in each of these four areas to identify the key gaps in research and to determine barriers against the commercialisation of geopolymer in Australia. Based on these analyses, effective and practical recommendations are proposed for future investigation avenues that may aid the industry adoption of geopolymer. Although focused on Australia due to the significant research initiative but yet low utilisation of fly ash and commercialisation of geopolymer concrete, this review is also applicable to other countries with low levels of fly ash utilisation or where low-quality fly ash is abundant, such as China [17], as well as many international markets where the substitution of OPC concrete with geopolymer could aid attainment of emissions reduction targets.

While it is noted that geopolymer research has yielded many different mix designs with varying precursor materials, this paper focuses only on geopolymer mixes utilising fly ash, with particular reference paid to low-quality fly ash sources such as brown coal fly ash as the main aluminosilicate source and alkaline solutions as the activating agent. This paper defines low-quality fly ash as fly ash currently lacking the requisite research base to determine its feasibility in a geopolymer mix, or which is not currently considered to be an adequate geopolymer precursor. Geopolymer research analysis has centred around research activities performed in the past decade. For each area proposed to impact the commercialisation of geopolymers in Australia, a review of relevant literature has been undertaken and associated research gaps and barriers to adoption identified, and recommendations for remediation suggested.

\section{Challenges and Recommendations for the Adoption of Geopolymers as Construction Materials}

\subsection{Material Properties}

The geopolymer reaction process requires a source material high in reactive alumina and silica [2] to precipitate a geopolymeric gel. Extensive research into both the suitability and availability of potential precursor materials has yielded fly ash as the most appropriate geopolymer source material [21]. There are two types of fly ash as classified by the American Society of Testing and Materials [22] based on the composition of the material; Type F and Type C. Type F fly ash is commonly derived from the burning of black coal, while Type $\mathrm{C}$ fly ash is commonly produced from sub-bituminous and brown coal, being is considered a lower quality fly ash source based on current research. Many Australian sources do not fit either category as their fly ash present low reactive $\mathrm{SiO}_{2}+\mathrm{Al}_{2} \mathrm{O}_{3}+\mathrm{Fe}_{2} \mathrm{O}_{3}$ $(<50 \%)$ or high $\mathrm{SO}_{3}$ content $(>5 \%)[17,23,24]$.

The properties of black coal fly ash (Type F)-based geopolymer material are appropriate for adoption in the construction industry due to the high strength and durability achieved in previous studies. Therefore, initial steps to the commercialisation of this type of fly ash have been taken through small-scale projects $[14,15]$, such as precast elements and in situ pavement works. The presence of these companies in the Australian market indicates that geopolymer synthesised from Type $\mathrm{F}$ fly ash is likely commercially viable. The body of research relating to the properties of Type F fly ash is extensive as shown by the early commercialisation efforts being undertaken.

Although brown coal makes up 40-55\% of coal burnt in Australia, from which approximately 1-2 million tonnes of ashes is generated per year (Figure 2) [16], the utilisation of brown coal fly ash in the construction industry is negligible [25]. This is predominantly due to the lower strength and durability achieved in select studies when compared to black coal fly ash-based geopolymer, due to brown coal fly ash's high $\mathrm{CaO}$ content, higher $\mathrm{SO}_{3}$ content, and lower amorphous content, which reduces reactivity [24]. Despite these limitations to the materials adoption, Australian brown coal fly ash-based geopolymers have shown promising strength results in several studies [17,23,25]. 

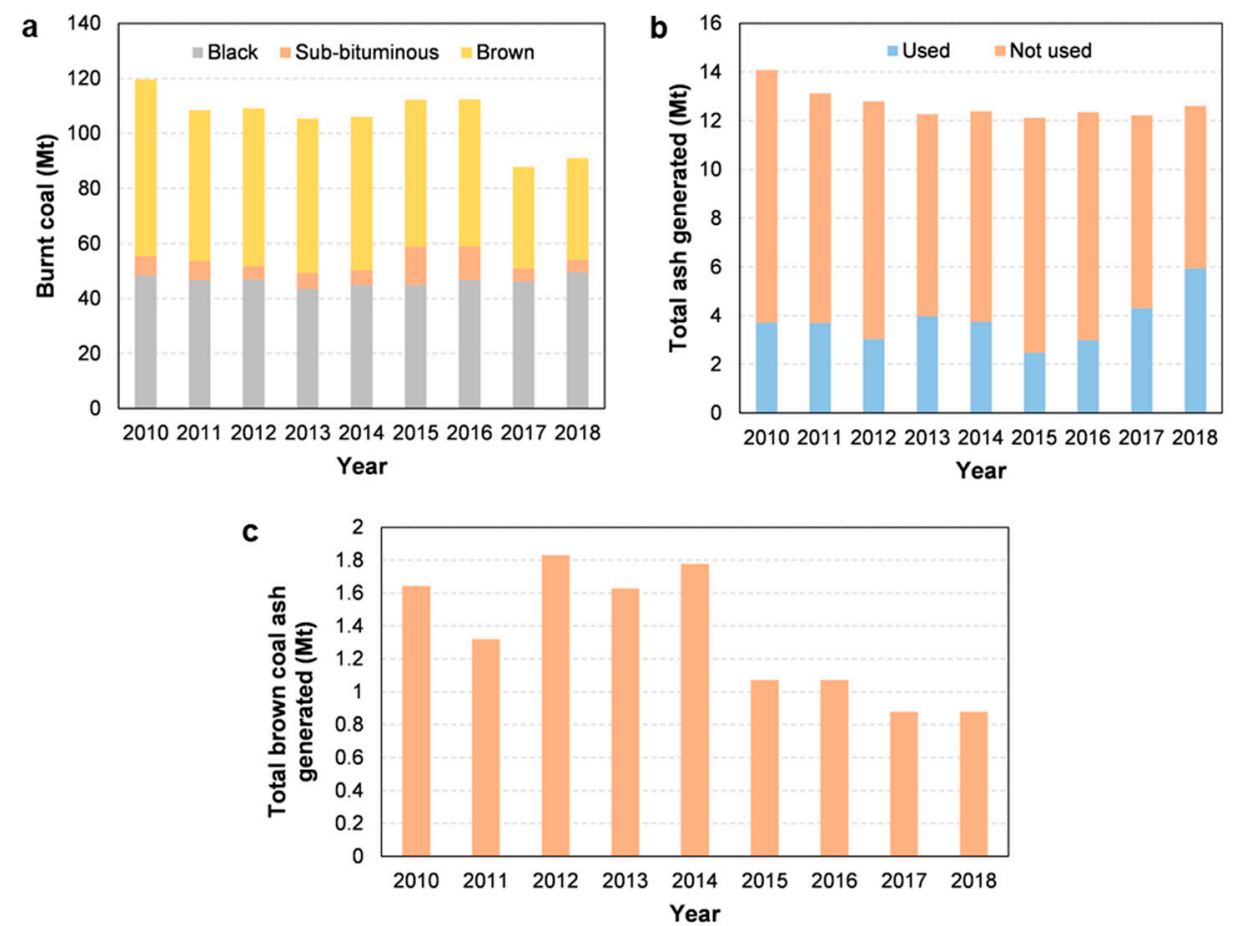

Figure 2. Quantity of burnt coal by type (a), total ash generated (b), and total brown coal fly ash generated (c) in Australia by year from 2010 to 2018. Data adapted from ref. [16].

The gap in research levels between brown and black coal fly ash-based geopolymer requires significant work to close. Between 2010 and 2018, Australia utilised approximately $20-45 \%$ of total fly ash generated [16], which is below the $50-60 \%$ rates of consumption in the US and India [17]. The gap between Australia's utilisation rate compared with that of India and America is possibly due to the high amount of the less researched, lower quality fly ash from sub-bituminous and brown coal sources. Common brown coal fly ash cannot currently be used in OPC concrete due to its mineralogy being incompatible with the current Australian Standards [25,26], which hampers its utilisation and reduces the overall fly ash utilisation of Australia. The development of geopolymer mixes with brown coal fly ash included as feedstock offers a possible circumvention of this issue.

The early stages of research carried out in Australia on the strength and durability of brown coal fly ash-based geopolymer can be classified into four steps, including:

- Particle size analysis: Smaller fly ash particle size has been shown to increase reactivity, early age, and long-term strength development of geopolymer [27,28].

- Amorphous content: Acceptable ranges for bulk mix mineralogy related to amorphous silica, alumina, and calcium oxide have been suggested [24,25]. The amorphous content in the bulk mix is also linked to activator chemical composition, with limits proposed by Dirgantara et al. [17].

- Acceptable fly ash sources: Brown coal fly ash from the Loy Yang coal-fired power plant is reportedly the most optimal for geopolymerisation among sources from the Australian state of Victoria [25] due to its chemical similarity to Type F fly ash.

- Additives: Blast furnace slag and Type F fly ash have been shown to improve geopolymer strength and durability while lowering activator volume requirements when used as partial additives to brown coal-based geopolymer [25].

While outcomes have varied during initial brown coal fly ash-based geopolymer studies, promising results have shown 28-day compressive strengths greater than $40 \mathrm{MPa}$ and 1-day strengths greater than $30 \mathrm{MPa}[17,24]$, similar to standard strength OPC concrete. On the other hand, information about the durability characteristics (e.g., resistance to fire, chemical attack) of the produced brown coal fly ash-based geopolymer is scarce. An initial investigation conducted by Tennakoon et al. [25] indicated that the water-resistance of 
brown coal fly ash-based geopolymer is impacted by the level of sulphate present in the mix. Nonetheless, further research is critical to understand the long-term stability of the developed geopolymer products and allow their commercialisation.

While research into the material properties (in particular the strength properties) of geopolymer has gained attention from academics, other areas require increased investigation to improve the utilisation and commercialisation of the technology. Paramount among these issues is the lack of consensus as to the bulk mix mineralogy requirements of geopolymer, which is especially critical for the less-understood field of brown coal-based geopolymer. While studies have proposed individual mix designs that show promising strength and durability characteristics (Table 1), the development of bulk mix requirements would allow far easier analysis of different fly ash sources and their suitability regarding different strength geopolymer designs, and it could pave the way for increased utilisation and commercialisation. Further testing and verification of the bulk mix chemical limits suggested by Tennakoon et al. [25] shown in Figure 3 are recommended as an initial step in this process.

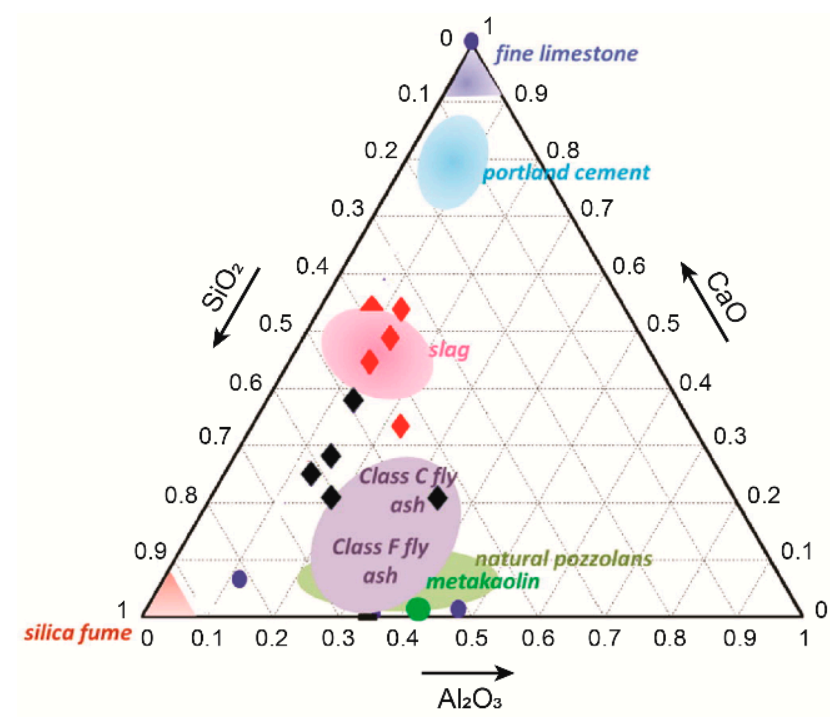

- $100 \%$ brown coal fly ash (<25 MPa)

Brown coal fly ash blending (> $25 \mathrm{MPa}$ )

Brown coal fly ash blending (> $25 \mathrm{MPa}$ )

- $100 \%$ slag (> $25 \mathrm{MPa})$

Figure 3. Chemical composition diagram with red markers indicating suggested brown coal geopolymer bulk mix chemistry. Reprinted with permission from ref. [25]. Copyright 2015 Elsevier.

Current research has centred around the use of liquid-activating solutions such as sodium silicate and sodium hydroxide; however, the liquid nature of these additives poses a barrier to commercialisation. Unlike concrete, water is not consumed in the geopolymer process [2], and thus, the addition of water through these liquid activators serves only to provide a medium for dry precursor material dissolution and the precipitation of a geopolymer paste. Due to the detrimental impact of water on geopolymer strength and durability [29], further study is recommended into the use of dry activators, such as sodium silicate and sodium hydroxide in powdered form. This would have the effect of more easily controlling the water content of geopolymer mixes in addition to potential physio-mechanical improvements on liquid-activated geopolymers as suggested by AbelGawwad and Abo-El-Enein [30], and while issues with the dissolution of the activator components may arise, this method requires further research prior to discounting. The use of dry activators would also allow for a "just add water" mix to be manufactured and batched [30], which is a critical component in the commercialisation of the product, as requiring specialised and corrosive chemicals such as sodium hydroxide to be poured into the mix on-site is both dangerous and impractical, and it would likely reduce the market for geopolymer powders being sold to the public by hardware stores due to the need for additional liquid activator purchases. For these reasons, increased understanding as to the validity of dry activator use is imperative to the commercialisation of geopolymer. 
Another issue hindering the utilisation of brown coal fly ash is the increased absorption of liquid activator due to a higher percentage of unburnt wood particles found in brown coal fly ash compared to black coal fly ash [25]. These particles do not add to the geopolymerisation process despite absorbing the activating solution, which reduces the proportion of activator available for the geopolymerisation process and increases the required amount of liquid activator. This issue culminates in increases to the water/solid ratio of the mix and lowered durability and strength characteristics [25]. To alleviate this issue and precipitate increased investment in the brown coal fly ash-based geopolymer sector, future research should investigate methods of fly ash pre-treatment that may reduce the activator absorption of these unburnt particles [31] to allow for increased reaction in the geopolymer matrix and to further assess the suitability of brown coal fly ash as a geopolymer precursor material. Xing et al. [31] suggested methods to reduce the proportion of unburnt particles in fly ash sources include sieving, electrostatic separation, and froth flotation; however, these alternatives need increased exploration to determine their economic viability.

Given the vast reserves and low cost of brown coal fly ash in Australia [16], increasing the utilisation of this material provides clear advantages for the commercialisation process through lower material cost when compared to black coal fly ash. Lower strength has been shown as a clear issue with brown coal-based geopolymers in Australia [17,25]; however, this should not preclude its use in the construction industry; short term future research should centre around non-structural applications for brown coal-based geopolymer with low strength requirements, which is a field shown to be promising by initial testing completed by Khodr et al. [23]. Research should also continue into mixes using a blend of brown coal and black coal fly ash's for higher strength applications, as suggested by Tennakoon et al. [24]. The testing and knowledge gained during lower-level structural utilisation in the short term can increase the likelihood of higher-level structural geopolymer made from brown coal fly ash being developed. As an example, concrete additives such as black coal fly ash and blast furnace slag, currently accepted as advantageous to concrete properties, were once believed to be only viable in small amounts [32]. It is suggested that a similar material development process can be mirrored in brown coal fly ash technology. Table 1 summarises some of the recent research activities on the utilisation of brown coal fly ash-based geopolymer in Australia.

Table 1. Summary of recent research activities on utilising brown coal fly ash-based geopolymer in Australia.

\begin{tabular}{cc}
\hline Approach & Results \\
\hline $\begin{array}{c}\text { Brown coal fly ash sourced from Victorian sources used as } \\
\text { feedstock in geopolymer mixes with varying amounts of } \\
\text { black coal fly ash and blast furnace slag also incorporated } \\
\text { into select mixes. Low heat curing was performed, and } \\
\text { samples were tested at one day. }\end{array}$ & $\begin{array}{c}\text { Brown coal fly ash shown to have poor strength } \\
\text { characteristics when used as the sole feedstock; however, } \\
\text { with black coal fly and blast furnace slag included to } \\
\text { target specific Si/Al ratios, 25-35 MPa strength mixes } \\
\text { were recorded }\end{array}$ \\
\hline $\begin{array}{c}\text { [ustralian brown coal fly ash used together with black } \\
\text { coal fly ash and slag to determine the bulk mix } \\
\text { mineralogy and links to strength }\end{array}$ & $\begin{array}{c}\text { Black coal fly ash and slag as supplementary feedstocks } \\
\text { increased the compressive strength. High sulphate } \\
\text { contents in brown coal fly ash were shown to have an } \\
\text { adverse effect on strength development. Brown coal fly } \\
\text { ash sources judged as acceptable or not based on } \\
\text { mineralogical properties, with these tests easily applied to } \\
\text { other fly ash sources to judge acceptability } \\
\text { [25 geopolymerisation. }\end{array}$ \\
\hline
\end{tabular}

Study using various brown coal fly ash from Victorian sources to develop a geopolymer mix. Altered activator quantities and different fly ash proportions were analysed, and brown coal fly ash was used as the only feedstock with heat curing performed
High-strength geopolymer was synthesised (up to

$50 \mathrm{MPa}$ ). The activator molarity was found to be important, as was the reactive elements in the fly ash when compared to the unreactive fly ash particles. 
Table 1. Cont.

\begin{tabular}{|c|c|c|}
\hline Approach & Results & Ref. \\
\hline $\begin{array}{l}\text { Attempts to synthesise low strength brown coal fly } \\
\text { ash-based geopolymer bricks for use in low-risk } \\
\text { applications. Brown coal fly ash used as the only feedstock }\end{array}$ & $\begin{array}{l}\text { Bricks consistently reached strengths of } 23 \mathrm{MPa} \text {, showing } \\
\text { suitability for low-strength applications. The particle size } \\
\text { and mineralogy of fly ash were shown to be important } \\
\text { factors in final strength development. }\end{array}$ & [23] \\
\hline $\begin{array}{l}\text { Brown coal fly ash was used in a particle size research } \\
\text { project relating to geopolymer strength. }\end{array}$ & $\begin{array}{l}\text { The brown coal fly ash used differed from most Australian } \\
\text { sources and was closer in mineralogy to common Type F } \\
\text { fly ash. Smaller particle size was found to increase the } \\
\text { strength through increased reactivity of the feedstock and } \\
\text { activating solution. }\end{array}$ & [27] \\
\hline $\begin{array}{l}\text { Brown coal fly ash was used as the sole feedstock to } \\
\text { develop a geopolymer mix. Particle size variance was } \\
\text { analysed for its effect on strength }\end{array}$ & $\begin{array}{l}\text { The brown coal fly ash used differed from most Australian } \\
\text { sources and was closer in mineralogy to common Type F } \\
\text { fly ash. Significant strength was recorded (134 MPa) with } \\
\text { smaller fly ash particle sizes. }\end{array}$ & [28] \\
\hline $\begin{array}{l}\text { Low calcium brown coal fly ash sourced from two } \\
\text { separate locations in the storage ponds of an Australian } \\
\text { power plant (Loy Yang) was used to manufacture } \\
\text { geopolymer mortars. }\end{array}$ & $\begin{array}{l}\text { The mortars with the two types of brown coal fly ash both } \\
\text { presented similar compressive strength at } 28 \text { days } \\
\text { (23-24 MPa). However, one type of fly ash displayed an } \\
\text { increase in strength development over time, while the } \\
\text { other displayed a decrease. }\end{array}$ & [33] \\
\hline $\begin{array}{l}\text { Geopolymer mortars were made with brown coal fly ash } \\
\text { sourced by the Yallourn power station in Australia. }\end{array}$ & $\begin{array}{l}\text { The mortars presented strengths varying from } 12 \text { to } \\
16 \mathrm{MPa} \text {. The obtained low strengths were associated with } \\
\text { the low alumina content coupled with the high unburnt } \\
\text { carbon content in the fly ashes. }\end{array}$ & [34] \\
\hline
\end{tabular}

\subsection{Economic Factors}

The economic constraints to the commercialisation of geopolymer are of paramount importance due to the fact that there will be hardly any adoption of geopolymer concrete on a meaningful scale unless it becomes financially competitive with OPC concrete. The body of literature for the economic factors surrounding geopolymer commercialisation is currently lacking. Research into the financial viability of geopolymer may not be solely performed by researchers, as companies can conduct independent cost-benefit analysis prior to undertaking any new business venture or operation. However, increased financial research may be a precipitator to more businesses paying attention to geopolymer as a potential sustainable structural replacement for traditional OPC concrete.

The supply chain for geopolymer, or lack thereof, is one of the most critical elements of an economically appealing geopolymer mix. In Australia, due to the large distances between major cities and the distance from overseas chemical producers, the minimisation of transport costs is extremely important. Increases in shipping and transit distances increase both the financial and environmental cost of geopolymer, lowering the commercial viability as well as the core advantage of geopolymer: its reduced emissions profile when compared to OPC concrete. As such, the need for financial analysis based on a predominantly local supply chain is extremely pertinent.

The current body of research on the economic factors affecting geopolymer in Australia has largely taken similar approaches, which comprise the estimation of the material, transport, mixing, and placing costs via a compilation of inventory data. McLennan et al. [6] considered four mix designs taken from past studies that yielded strength similar to the OPC concrete tested and estimated their total mix design costing, with comparisons made to the cost of OPC concrete. Figure 4 shows the estimated cost and associated GHG emissions of the potential geopolymer mixes. The results indicated that geopolymer has costs ranging from $7 \%$ cheaper to $39 \%$ more expensive than OPC concrete in Australia with the critical cost factors found to be black coal fly ash, sodium silicate, and transport costs. 

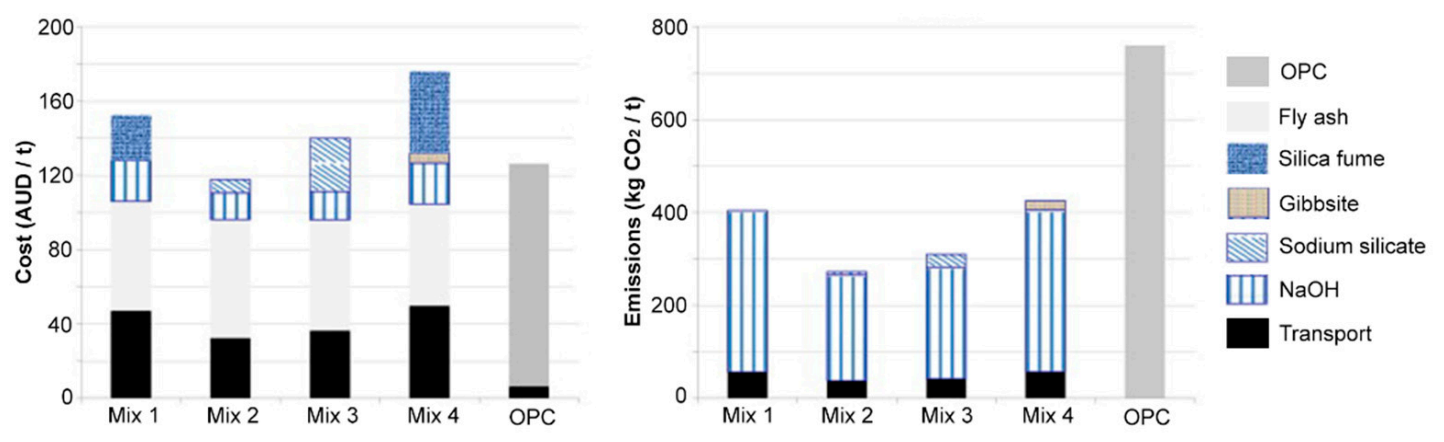

Figure 4. Cost and greenhouse gas (GHG) emission per tonne of different geopolymer mixes in comparison with Ordinary Portland Cement (OPC). Reprinted with permission from ref. [6]. Copyright 2011 Elsevier.

This holistic approach to geopolymer cost estimation was mirrored by Chan et al. [35], who included a 20-year life cycle analysis to compare OPC and geopolymer costs, which included hypothesised capital outlay requirements to set up geopolymer batching plants. For the analysis, a general equation was developed comprising the capital cost, costs related to manufacturing, material variability, lifelong operations, maintenance, disposal, and environmental taxes, in addition to the residual value of the material (for further details on the equations, see ref. [35]). The study found that OPC was around $18 \%$ cheaper than geopolymer of the same strength, with the geopolymer cost increases coming predominantly from higher source material price compared to OPC concrete. Both studies indicate that lowering the cost of geopolymer precursors, particularly sodium hydroxide and sodium silicate, can greatly improve the financial viability of geopolymer.

The economic factors explored in the past Australian studies contained gaps that new research should fill. The most glaring issue in the research base is the age of the literature; the results reported in Chan et al. [35] and McLennan et al. [6] are now 6 and 10 years old, respectively. It is probable that the figures for material and transport costs have changed due to market forces and inflation. A study updating researchers and industry as to the current cost of geopolymer in Australia is vital to shedding light on the current viability of the technology, as continued investigation into the material properties of strength and durability is rendered largely mute unless the forecast cost of geopolymer can be reasonably competitive to OPC.

Another limitation to past research is the lack of clarity over what quantities and materials are estimated in the quoted costs of geopolymer. Chan et al. [35] did not provide details of the mix designs used to form cost estimates, making a comparison to other past and future reported figures difficult. Confidence in the cost estimates of geopolymer can only be achieved when a "standard" strength bulk mix design is agreed upon as discussed in the previous section. Until a consensus relating the chemistry of the mix designs with all source materials added to the final strength of geopolymer can be found, the economic analysis will present a high level of uncertainty.

Mix design uncertainty also impacts the development of supply chain forecasts. Past research into the costs of Australian geopolymer assumes all fly ash sources, the locations of which are shown in Figure 5, are acceptable as geopolymeric material. This assumption is not accurate with current geopolymer understanding. In the Australian state of Victoria, where several coal power stations in the LaTrobe Valley burn brown coal from similar geography, the resulting fly ash varies greatly in chemistry $[17,25]$ due to the mineralogical variances between the coal seams these stations excavate from [36]. As such, and with a mind to the minimisation of transport costs as discussed previously, a database of acceptable fly ash sources should be compiled through chemical testing or cross-referencing with past experiments to allow for more accurate transport costs and supply chains to be developed between these source locations and nearby high-concrete usage areas. Continued economic research acting under the assumption that all Australian fly ash deposits are acceptable source locations risk underestimating the cost of geopolymer, as transport costs 
will likely be undervalued in some cases. An important caveat to this current issue in the literature is the theory that with increased research and practice comes a likely increase in utilisable fly ash sources.

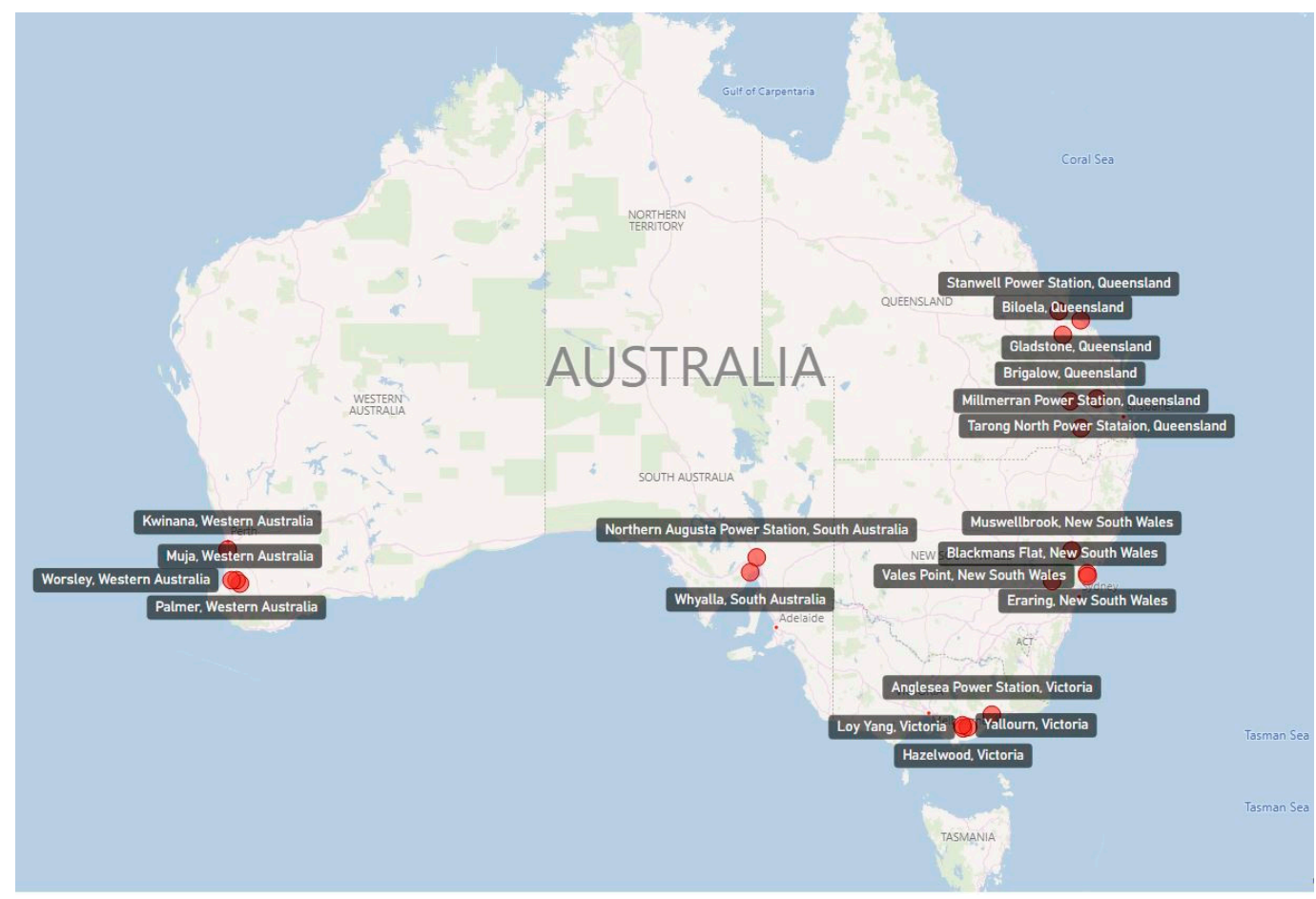

Figure 5. Locations of fly ash sources in Australia.

The past geopolymer cost analysis has been compared to the current cost of a similar strength OPC concrete. While the current prices of concrete indicate that geopolymer is in most cases less cost-effective than OPC of similar strength, past reports have not included any contingency for cost increases due to a reduced domestic supply proportion of cement or future governmental prices or taxes on carbon emissions. Australia has increased the proportion of clinker imported, which is the base material used to make cement, steadily over the past 7 years, putting upwards pressure on cement prices through increased transport costs exacerbated by rising demand due to the construction boom occurring in parts of Australia [37]. With demand expected to continue to grow due to high population growth and large infrastructure projects being undertaken [18], this price rise is expected to continue, which may make geopolymer more cost-effective in comparison as time goes on. Similarly, a price or tax on carbon for high-emission producers as debated in the 2019 Australian federal election and adopted in Canada, Japan, and parts of the European Union may also increase the cost of cement in Australia due to the significant carbon footprint of concrete production [38]. Both factors may contribute to concrete price rises, and as such, any future economic research of geopolymer should include sensitivity analysis to determine the effect of possible concrete cost increases on the economic viability of geopolymer.

Similar to the static cost estimations used in past research for concrete, the cost of geopolymer has not included sensitivity analysis for forecasted future price changes in Australia. Geopolymer represents a promising field that in the best-case scenario, will rival concrete as a construction material with a far better emissions profile, and the price for geopolymer components will adjust due to heightened demand. At the current time, black coal fly ash comes with associated costs [6,35]; however, brown coal fly ash is without a well-established cost. Future research needs to provide price estimates for both of these vital precursor materials based on expected future demand and supply, and it needs to use these values in sensitivity analysis to better estimate the forecasted price of geopolymer 
mixes in Australia and more accurately guide the emerging industry as to the economic viability. The geopolymer feedstock base, if limited only to high-quality black coal fly ash, will likely experience a higher rate of price increase, as the supply of these ashes will be shared with the OPC industry, and their demand is expected to increase [37]. This potential price issue further highlights the need for brown coal fly ash-based geopolymer research to allow more fly ash sources to supply the fledgling geopolymer market and reduce upward pressure on geopolymer prices.

The economic feasibility of using recycled materials in geopolymer is a field that also needs further investigation to aid the commercialisation of geopolymer products. For example, an increasing body of research is focusing on the use of recycled alkaline sources as the activating agent in geopolymer mix design, such as calcium carbide residue from the acetylene production process [39,40]. Cost and life-cycle analyses in Thailand demonstrate that the alkali-activated high-calcium fly ash mortars with recycled calcium carbide residue can be cost-effective compared to Portland cement materials, in addition to presenting good engineering performance (Figure 6). Nevertheless, while the increased usage of recycled materials to replace the emissions and cost-intensive activators currently used [6] is likely beneficial for the emissions profile of geopolymer, the costs of these recycled materials and their impacts on the economic viability of geopolymer mix designs in Australia are largely unknown.

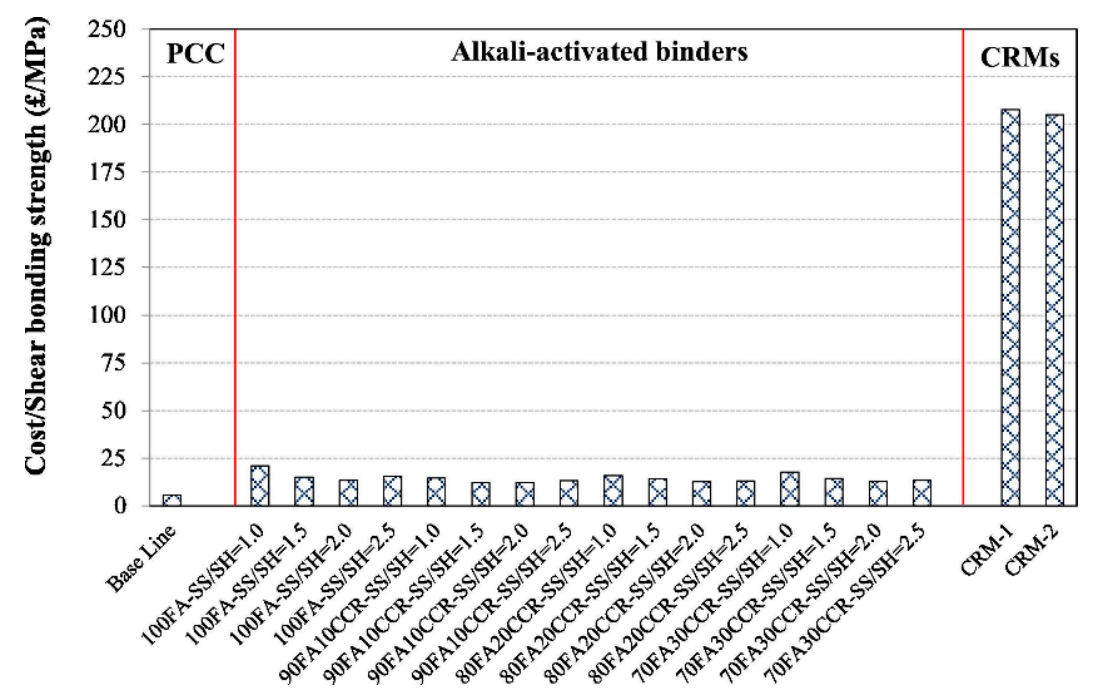

Figure 6. Cost analysis of alkali-activated high-calcium fly ash/recycled calcium carbide mortars as commercial repair materials. PCC-Portland cement concrete; CRM-Conventional repair materials; FA—Fly ash; CCR—Calcium carbide residue; SS—Sodium silicate; SH—Sodium hydroxide. Reprinted with permission from ref. [39]. Copyright 2020 Elsevier.

While it is foreseeable that continued rising costs of concrete in conjunction with improvements relating to the material properties of geopolymer may see geopolymer become cost-competitive with OPC concrete, there still may not be the required incentives for the construction industry to adopt the new technology. Geopolymer concrete manufacturing is capital intensive processes requiring significant investment in plant, equipment and supply chains, and geopolymer will likely need to exhibit a lower cost with comparable material properties for the construction industry to switch their operations and capital into this new material. Rising emissions are not purely the construction industry's responsibility, and as such, federal or state governments may consider subsidising the initial capital outlay required to set up the requisite infrastructure to create a cost-competitive geopolymer mix. Public money assisting in efforts to "green" heavy emitting industries is not a new concept and reflects the fact that organisations should arguably be rewarded for reducing 
large-scale emissions, and thus providing an otherwise unrewarded benefit to the national and global population through reduced global warming.

\subsection{Social Attitudes}

Geopolymer technology provides a significant opportunity to meaningfully reduce the carbon emissions produced by the construction industry through the replacement of current high-emission OPC concrete utilised worldwide. However, the broad commercialisation required to realise this opportunity hinges on the societal attitudes towards this new and largely unknown construction material. While the material properties and economic factors are the most important barriers to commercialisation, the public perception of the technology may greatly impact the prevalence of geopolymer in the short term while a convincing body of evidence proving geopolymers strength and stability is compiled.

The key challenge geopolymer technology must overcome regarding social attitudes is to be seen as a safe alternative to OPC concrete, which is a universally trusted construction material. OPC concrete is the most consumed manufactured material in the world [37], and its widespread and long-term use has created trust in its use as a construction material, as previous concrete structures provide evidence regarding its structural safety. This implicit trust in concrete based on years of use is not something that geopolymer can replicate in the short to medium term, and as such, future geopolymer structures will be more scrutinised by both regulatory bodies and the public compared with OPC structures.

Current and previous geopolymer research has, for good reason, focused largely on developing the understanding of the mechanical properties of the material, namely the strength and durability characteristics. While geopolymer synthesised from brown coal fly ash still has significant research required in this area, the infant commercialisation of black coal fly ash-based geopolymer $[14,15]$ provides a need for thought to be given as to how the general public will accept a new construction material in more mainstream use, especially in high rise and major infrastructure projects, where trust in structural stability is paramount in users' minds. At present, there has been no meaningful research into how geopolymer would be viewed and accepted by the general public as a structural material. This is understandable given the fledgling stage of the market; however, continuing to ignore this potential barrier to commercialisation may prove detrimental to the adoption of geopolymer technology in the near future.

The importance of social acceptance for new construction technologies should not be underestimated. Lehmann [41] suggested that changing ingrained behaviours and preferences is the biggest barrier to the adoption of new technologies, and this may be especially true in the case of geopolymer, as attempting to replace such an implicitly trusted material such as concrete represents a significant shift in societal preferences. The magnitude of this barrier can be estimated through analysis of the high-rise timber structure movement and the impact that societal attitudes have had in preventing this environmentally friendly technology from achieving widespread adoption. High rise wooden structures made from Cross-Laminated Timber (CLT) have been seen by some as a low emissions alternative to concrete, and they have been shown to possess comparable strength at a lower weight; however, widespread adoption has been hindered significantly by social acceptance of the material, especially in regions where existing large buildings are almost exclusively made out of concrete [42]. The similarities between CLT and geopolymer in terms of societal attitudes are clear, with both technologies benefitting from a greater interest by consumers in environmentally conscious building technologies and practices [43], and public reluctance to preference CLT structures based on the perceived safety advantages of concrete [42] is likely to be mirrored in the commercialisation of geopolymer.

Future research into this area is recommended to investigate and quantify how social attitudes can impact the commercialisation process in Australia, which is likely through surveys on construction companies and the general public to gauge the appetite for a new construction material. Future research should yield estimates into the commercial timelines available for the emerging industry, as a societal lag in accepting the material will 
likely create a period between when companies begin to make structural and commercially viable geopolymer mixes, and when these mixes are used in high rise and large-scale infrastructure projects.

Targeted marketing techniques may prove important in this regard, as highlighting the similarities between geopolymer and concrete to construction firms and the general public may lessen the negative social reactions restricting widespread adoption. This strategy of reducing the perceived differences to traditional concrete has been implemented by businesses through the naming of "E-crete" geopolymer [44] and "Earth Friendly Concrete" products [15] (Figure 7). Marketing may also help the commercialisation effort by showcasing the small scale pours already being undertaken in Australia and worldwide.
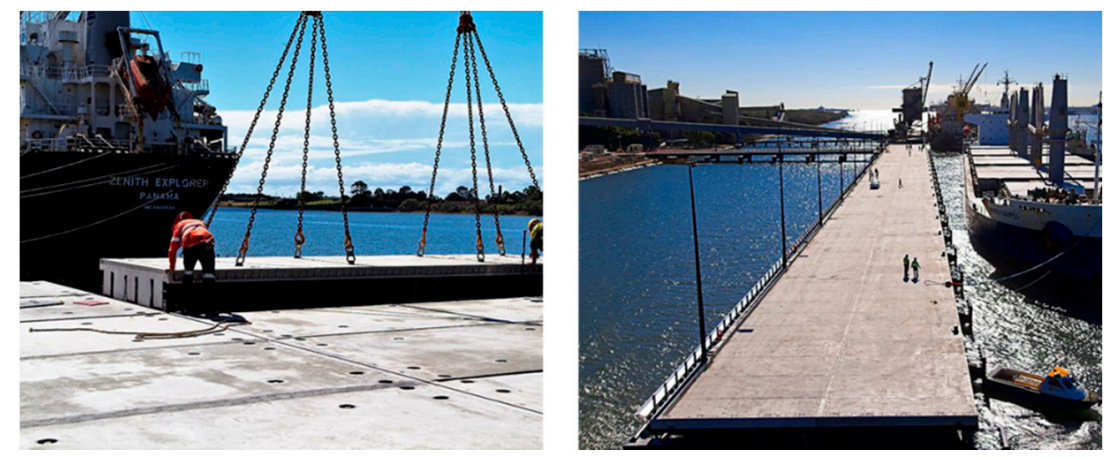

Figure 7. Use of geopolymer precast panels, named as "Earth Friendly Concrete", in the construction of a wharf on the Brisbane River at Pinkenba, Queensland. Reprinted with permission from Wagners [45]. Copyright 2021 Wagners.

\subsection{Regulatory Environment}

The choice of construction materials in practice is heavily reliant on the regulatory environment, in particular the governing standards relating to required strength and durability. The Australian construction industry adheres to Australian Standards (AS) throughout design and construction works, and current standards have detailed and easily replicable instructions for the specification and installation of structural concrete elements through AS3600-2018 [46] and AS1379-2007 [47]. Cement, the precursor material to concrete, also has detailed and narrow chemical composition ranges specified through AS3972-2010 [48]. The highly standardised nature of the cement and concrete regulatory environment in Australia gives clear guidelines to suppliers and construction companies, in addition to allow organisations to reliably forecast and estimate projects based on cost and material choice with the knowledge that there is very little probability that the material will fail to perform to expectations.

The current regulatory standards for the specification and synthesis of geopolymer is minimal. The overarching Australian Standards do not yet contain specific sections or clauses related to geopolymer, meaning its use in the Australian construction industry requires case-by-case approval. The most common precursor to geopolymer, fly ash, has a regulatory document for its specification, AS3582.1:2016 [26]. This standard details the selected minimum and maximum chemical and material properties; however, it only relates to the use of fly ash as a partial substitute to cement in the production of traditional concrete, and the inclusion of fly ash is limited to $10 \%$ of the mass in various cement types as per AS3972-2010 [48].

Other regulatory publications relating to geopolymer have been developed, indicating an emerging field of research. VicRoads, Victoria's chief road authority, has specified geopolymer as an acceptable alternative for concrete in works requiring a non-structural material within the following standards [49-53]:

- Section 701-Underground stormwater drains;

- Section 703-General concrete paving;

- Section 705-Drainage pits; 
- Section 708-Steel beam guard fence; and

- Section 711-Wire rope safety barrier.

The strength requirements based on these standards range from 20 to $32 \mathrm{MPa}$, and the fly ash precursor used in the production of the geopolymers specified must adhere to the chemical and material parameters set out in AS3582.1. These VicRoads standards also require $80 \%$ of the mix to be fly ash and set out a high-level mixing and placement methodology to be followed during the geopolymer pour.

Independent research is also underway in the development of a set of geopolymer standards. Mendt et al. [54] presented an update on attempts to formalise a handbook detailing the specifications and construction requirements of geopolymer in conjunction with the Ash Development Association of Australia.

The current standardisation research and regulatory environment in Australia represent many barriers to commercialisation. Due to a lack of clear and regulatory approved standards guiding mixing and placing techniques, chemical and material property stipulations, and durability testing methods, new entrants to the geopolymer supply market need to conduct independent literature reviews and testing, which are both very timeconsuming processes. Companies currently supplying geopolymer are also hamstrung by the key standard organisation in Australia, Standards Australia, which is not yet recognising geopolymer as a construction material in its own right, and thus, current avenues for sale are largely centred around VicRoads projects and isolated private pours [15,55].

The development of new construction material standards is a very long process, as there must be adequate regulatory confidence in both the technology and the compiled standards to ensure safe production of the new material. While a comprehensive geopolymer standard setting out the design process for high-strength geopolymer structural elements to rival AS3600 is likely to take many years to compile, there are shorter-term regulatory actions that can increase the rate of commercialisation in Australia. VicRoads' standard sections have allowed for geopolymer to be used in construction works, and the use of low-strength geopolymer in a low-risk environment should be encouraged through an update to the following regulatory documents, to bring the Australian Standards in line with those adopted by VicRoads:

- AS3727.1: Pavements-Residential; and

- AS3500.3: Stormwater drainage.

If these standards can be amended to include geopolymer as an acceptable lowstrength construction material, this could incentivise new companies to enter the market throughout Australia, instead of geopolymer adoption being kept largely in Victoria due to VicRoads' regulatory leadership.

Current concrete Australian Standards rely on a prescriptive approach, which details chemical and material property limits for the individual components used in the concrete mix to achieve the desired strength or use. Due to the extreme variability in fly ash mineralogy from different sources $[17,25]$, the utility of developing a set of geopolymer standards through a similar prescriptive approach is low, as although many different fly ash types may be acceptable as geopolymer precursor materials by changing the overall mix design, a prescriptive standard would eliminate many fly ash sources that did not "fit the mould". This is an issue that plagues current commercialisation efforts, as although the VicRoads standards allow for geopolymer use in certain construction projects, the fly ash must still adhere to the chemical and material properties set out in AS3582.1. This prescriptive method is a short-sighted approach, as fly ash is only one component in the geopolymer process, and many fly ashes' mineralogy is different to the requirements set out in AS3582.1, which have been shown to produce adequate strength geopolymer $[17,24,25]$.

The altering of the prescriptive method found in current Australian Standards to a performance-based standard, which accepts the use of geopolymer mixes based on their past performance instead of fly ash mineralogy, would increase the number of fly ash sources available to geopolymer suppliers, and it would be expected to lower the cost of production and incentivise future commercialisation. However, if a prescriptive approach 
must be set, another alternative practice may be to set chemical limits not on the fly ash, but on the bulk mix design instead, such as amorphous content minimums for key chemical components such as $\mathrm{SiO}_{2}, \mathrm{Al}_{2} \mathrm{O}_{3}$, and $\mathrm{CaO}$ as suggested by Tennakoon et al. [25]. This method would acknowledge that geopolymer mixes can contain multiple types of fly ash or other additives such as Granulated Blast Furnace Slag, and it would also have the desired effect of increasing the number of acceptable fly ash sources available to suppliers.

Figure 8 presents a summary of the recommended pathways discussed in this work for the commercialisation of geopolymer cement/concrete in Australia.

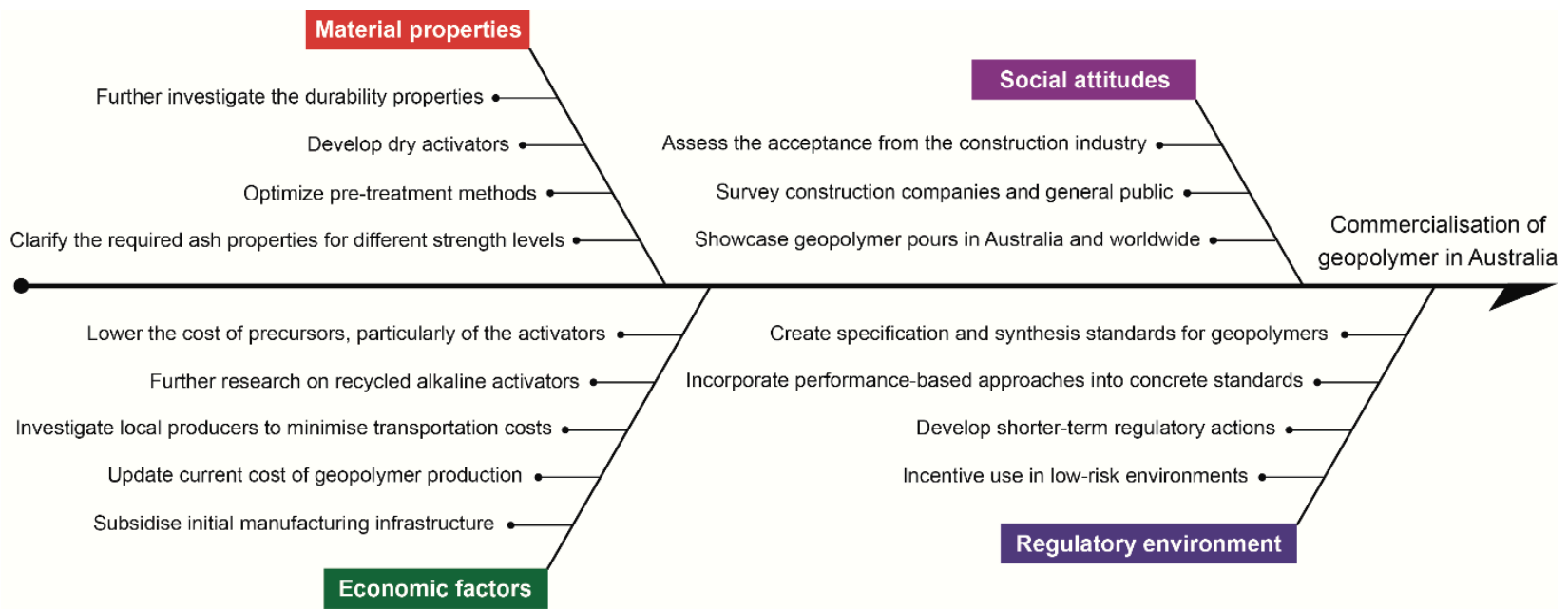

Figure 8. Summary of recommendations for adoption of geopolymers as a construction material in Australia.

\section{Conclusions}

Geopolymer technology in Australia is an emerging industry that poses substantial environmental advantages over incumbent construction materials such as OPC concrete. However, significant barriers to commercialisation and wider adoption in the Australian market are limiting short-term utilisation. Our investigation on the recent research and development of geopolymer in Australia indicated that the key barriers to geopolymer commercialisation in Australia and associated recommendations for future research include the following:

- Material properties: Usage of large reserves of brown coal fly ash in Australia is minimal due to lower strength development and higher activator absorption compared to black coal fly ash-based geopolymer. Issues regarding the suitability of dry activators and the development of bulk mix chemical limits are also prevalent. These areas require increased research, as do the merits of low-strength applications of brown coal fly ash-based geopolymer.

- Economic factors: Age of economic analysis in conjunction with issues relating to acceptable fly ash sources used in modelling both present issues for businesses looking to leverage research to guide future investment. Future research should fill these gaps as well as provide contingencies for price changes to both geopolymer and concrete, which can guide industry and governments to determine the relevant incentives required to proliferate the technology.

- Social attitudes: Lack of research in this area presents uncertainty as to how the general public and construction industry will react to geopolymer use in structural applications. Future research should analyse the societal attitudes to geopolymer and possible impacts of marketing.

- Regulatory environment: The lack of an overarching Australian Standard permitting the use of geopolymer in select construction projects limits nation-wide commercialisation efforts, as do the prescriptive-based limitations on acceptable fly ash chemistry. 
Future standards should focus on a performance-based approach to identify adequate geopolymer mixes.

Author Contributions: Conceptualisation, E.S. and O.B.; methodology, E.S. and O.B.; investigation, O.B.; writing-original draft preparation, E.S. and O.B.; writing—review and editing, F.B.d.S., E.B., K.S.-C. and J.S.; visualisation, O.B. and F.B.d.S.; supervision, E.S. All authors have read and agreed to the published version of the manuscript.

Funding: This research received no external funding.

Institutional Review Board Statement: Not applicable.

Informed Consent Statement: Not applicable.

Acknowledgments: The authors would like to recognise the invaluable insights into the fly ash and geopolymer industries from Brian Davey from Australian Carbon Innovation.

Conflicts of Interest: The authors declare no conflict of interest.

\section{References}

1. IEA. Cement Technology Roadmap Plots Path to Cutting CO2 Emissions 24\% by 2050. Available online: https://www.iea.org/ newsroom/news/2018/april/ cement-technology-roadmap-plots-path-to-cutting-co2-emissions-24-by-2050.html (accessed on 4 March 2021).

2. Davidovits, J.; Cordi, S. Synthesis of new high temperature geo-polymers for reinforced plastics/composites. SPE PACTEC 1979, 79, 151-154.

3. Singh, B.N. Fly ash-based geopolymer binder: A future construction material. Minerals 2018, 8, 299. [CrossRef]

4. Teh, S.H.; Wiedmann, T.; Castel, A.; de Burgh, J. Hybrid life cycle assessment of greenhouse gas emissions from cement, concrete and geopolymer concrete in Australia. J. Clean. Prod. 2017, 152, 312-320. [CrossRef]

5. Karantonis, J.L. The Hazards of Fly Ash. UNSW Canberra ADFA J. Undergrad. Eng. Res. 2012, 4, 1-11.

6. McLellan, B.C.; Williams, R.P.; Lay, J.; van Riessen, A.; Corder, G.D. Costs and carbon emissions for geopolymer pastes in comparison to ordinary portland cement. J. Clean. Prod. 2011, 19, 1080-1090. [CrossRef]

7. Turner, L.K.; Collins, F.G. Carbon dioxide equivalent (CO2-e) emissions: A comparison between geopolymer and OPC cement concrete. Constr. Build. Mater. 2013, 43, 125-130. [CrossRef]

8. Sandanayake, M.; Gunasekara, C.; Law, D.; Zhang, G.; Setunge, S.; Wanijuru, D. Sustainable criterion selection framework for green building materials-An optimisation based study of fly-ash Geopolymer concrete. Sustain. Mater. Technol. 2020, 25, e00178. [CrossRef]

9. Rahman, S.K.; Al-Ameri, R. A newly developed self-compacting geopolymer concrete under ambient condition. Constr. Build. Mater. 2021, 267, 121822. [CrossRef]

10. Pham, T.M.; Liu, J.; Tran, P.; Pang, V.-L.; Shi, F.; Chen, W.; Hao, H.; Tran, T.M. Dynamic compressive properties of lightweight rubberized geopolymer concrete. Constr. Build. Mater. 2020, 265, 120753. [CrossRef]

11. Gildenhuys, H. Pioneering a New Approach to Sustainable Concrete in Western Australia: Geopolymer Concrete from Fly-Ash with Recycled Aggregates. Bachelor's Thesis, Murdoch University, Perth, Australia, 6 December 2020.

12. Van Jaarsveld, J.; van Deventer, J.; Schwartzman, A. The potential use of geopolymeric materials to immobilise toxic metals: Part II. Material and leaching characteristics. Miner. Eng. 1999, 12, 75-91. [CrossRef]

13. Van Deventer, J.S. The conversion of mineral waste to modern materials using geopolymerisation. In Proceedings of the MINPREX 2000 International Congress on Mineral and Processing and Extractive Metallurgy, Melbourne, Australia, 1 January 2000; The Australian Institute of Mining and Metallurgy: Melbourne, Australia, 2000; pp. 11-13.

14. Van Deventer, J.S.J.; Feng, D.; Duxson, P. Dry Mix Cement Composition, Methods and Systems Involving Same. U.S. Patent 7691198B2, 6 April 2010.

15. Wagners Earth Friendly Concrete (EFC). Geopolymer Concrete. Available online: https://www.wagner.com.au/media/1519 / efc-factsheet.pdf (accessed on 4 March 2021).

16. HBM Group Pty Ltd. Ash Development Association of Australia, Annual Membership Survey Results 2018; ADAA National Office: Wollongong, Australia, 2019.

17. Dirgantara, R.; Gunasekara, C.; Law, D.W.; Molyneaux, T.K. Suitability of brown coal fly ash for geopolymer production. J. Mater. Civ. Eng. 2017, 29, 04017247. [CrossRef]

18. CCAA. AUSTRALIA'S CONCRETE INDUSTRY REPORTS RECORD PRODUCTION YEAR. Available online: https://www.ccaa. com.au/imis_prod/documents/271118_NAT_FIGURES_REVEAL_BIG_BOOM_IN_HEAVY_MATERIALS.pdf (accessed on 4 March 2021).

19. Yu, M.; Wiedmann, T.; Crawford, R.; Tait, C. The carbon footprint of Australia's construction sector. Procedia Eng. 2017, 180, 211-220. [CrossRef] 
20. Zhuang, X.Y.; Chen, L.; Komarneni, S.; Zhou, C.H.; Tong, D.S.; Yang, H.M.; Yu, W.H.; Wang, H. Fly ash-based geopolymer: Clean production, properties and applications. J. Clean. Prod. 2016, 125, 253-267. [CrossRef]

21. Nazari, A.; Sanjayan, J.G. Handbook of Low Carbon Concrete; Butterworth-Heinemann: Oxford, UK, 2016.

22. American Society for Testing and Materials. Standard Specification for Coal Fly Ash and Raw or Calcined Natural Pozzolan for Use in Concrete; ASTM International: West Conshohocken, PA, USA, 2013.

23. Khodr, M.; Law, D.; Gunasekara, C.; Setunge, S. Initial Development of Brown Coal Fly Ash Geopolymer Concrete Bricks. In Proceedings of the 28th Biennial National Conference of the Concrete Institute of Australia, Adelaide, Australia, 22-25 October 2017.

24. Tennakoon, C.; Sagoe-Crentsil, K.; Sanjayan, J.G.; Shayan, A. Early Age Properties of Alkali Activated Brown Coal Fly ash binders. Adv. Mater. Res. 2014, 931-932, 457-462. [CrossRef]

25. Tennakoon, C.; Sagoe-Crentsil, K.; San Nicolas, R.; Sanjayan, J.G. Characteristics of Australian brown coal fly ash blended geopolymers. Constr. Build. Mater. 2015, 101, 396-409. [CrossRef]

26. Standards Australia. AS/NZS 3582.1:2016-Supplementary Cementitious Materials; Part 1: Fly Ash; SAI Global Limited: Sydney, Australia, 2016.

27. Mucsi, G.; Molnar, Z.; Kumar, S. Geopolymerisation of Mechanically Activated Lignite and Brown Coal Fly Ash. Acta Phys. Pol. A. 2014, 126. [CrossRef]

28. Rieger, D.; Kullová, L.; Čekalová, M.; Novotný, P.; Pola, M. Mechanically activated fly ash as a high performance binder for civil engineering. J. Phys. Conf. Ser. 2017, 790, 012030. [CrossRef]

29. Ismail, I.; Provis, J.; Van Deventer, J.; Hamdan, S. The effect of water content on compressive strength of geopolymer mortars. In Proceedings of the AES-ATEMA'2011 International Conference on Advances and Trends in Engineering Materials and Their Applications, Milan, Italy, 4-8 July 2011.

30. Abdel-Gawwad, H.; Abo-El-Enein, S. A novel method to produce dry geopolymer cement powder. HBRC J. 2016, 12, 13-24. [CrossRef]

31. Xing, Y.; Guo, F.; Xu, M.; Gui, X.; Li, H.; Li, G.; Xia, Y.; Han, H. Separation of unburned carbon from coal fly ash: A review. Powder Technol. 2019, 353, 372-384. [CrossRef]

32. Thomas, M. Optimizing the Use of Fly Ash in concrete; Portland Cement Association Skokie IL: Skokie, IL, USA, 2007; Volume 5420.

33. Khodr, M.; Law, D.W.; Gunasekara, C.; Setunge, S.; Brkljaca, R. Compressive strength and microstructure evolution of low calcium brown coal fly ash-based geopolymer. J. Sustain. Cem. Based Mater. 2020, 9, 17-34. [CrossRef]

34. Khodr, M.; Law, D.W.; Gunasekara, C.; Setunge, S. Reactivity and Performance of Alkali-Activated Yallourn Brown Coal Ash. ACI Mater. J. 2020, 117, 149-158. [CrossRef]

35. Chan, C.; Thorpe, D.; Islam, M. An evaluation of life long fly ash based geopolymer cement and ordinary Portland cement costs using extended life cycle cost method in Australia. In Proceedings of the 2015 IEEE International Conference on Industrial Engineering and Engineering Management (IEEM), Singapore, 6-9 December 2015; pp. 52-56.

36. Holdgate, G.R. Geological processes that control lateral and vertical variability in coal seam moisture contents-Latrobe Valley (Gippsland Basin) Australia. Int. J. Coal Geol. 2005, 63, 130-155. [CrossRef]

37. Cement Industry Federation. Australian Cement Report. Available online: http://cement.org.au/wp-content/uploads/2020/0 8/CIF-Industry-Report-2020.pdf (accessed on 30 March 2021).

38. Macdonald-Smith, A.; Potter, B. LNG, Steel, Cement to Be Hit by Labor's Carbon Plan. Available online: https:/ /www.afr.com/ politics / federal/lng-steel-cement-to-be-hit-by-labor-s-carbon-plan-20190401-p519kr (accessed on 30 March 2021).

39. Phoo-ngernkham, T.; Phiangphimai, C.; Intarabut, D.; Hanjitsuwan, S.; Damrongwiriyanupap, N.; Li, L.-Y.; Chindaprasirt, P. Low cost and sustainable repair material made from alkali-activated high-calcium fly ash with calcium carbide residue. Constr. Build. Mater. 2020, 247, 118543. [CrossRef]

40. Phetchuay, C.; Horpibulsuk, S.; Suksiripattanapong, C.; Chinkulkijniwat, A.; Arulrajah, A.; Disfani, M.M. Calcium carbide residue: Alkaline activator for clay-fly ash geopolymer. Constr. Build. Mater. 2014, 69, 285-294. [CrossRef]

41. Lehmann, S. Sustainable construction for urban infill development using engineered massive wood panel systems. Sustainability 2012, 4, 2707-2742. [CrossRef]

42. Mallo, M.F.L.; Espinoza, O.A. Outlook for cross-laminated timber in the United States. BioResources 2014, 9, 7427-7443.

43. Dodge Data \& Analytics. World Green Building Trends 2018. Available online: https://www.worldgbc.org/sites/default/files/ World\%20Green\%20Building\%20Trends\%202018\%20SMR\%20FINAL\%2010-11.pdf (accessed on 4 March 2021).

44. The Zeobond Group. E-crete Brochure. Available online: http://www.zeobond.com/downloads/E-Crete_brochure.pdf (accessed on 4 March 2021).

45. Wagners. Pinkenba Wharf. Available online: https://www.wagner.com.au/main/our-projects/pinkenba-wharf/ (accessed on 29 March 2021).

46. Standards Australia. AS3600:2018—Concrete Structures; SAI Global Limited: Sydney, Australia, 2018.

47. Standards Australia. AS 1379-2007-Specification and Supply of Concrete; SAI Global Limited: Sydney, Australia, 2007.

48. Standards Australia. AS 3972-2010—General Purpose and Blended Cements; SAI Global Limited: Sydney, Australia, 2010.

49. VicRoads. Section 705—Drainage Pits; VicRoads: Melbourne, Australia, 2013.

50. VicRoads. Section 701-Underground Stormwater Drains; VicRoads: Melbourne, Australia, 2015.

51. VicRoads. Section 703—General Concrete Paving; VicRoads: Melbourne, Australia, 2016. 
52. VicRoads. Section 711-Wire Rope Safety Barrier (WRSB); VicRoads: Melbourne, Australia, 2017.

53. VicRoads. Section 708-Steel Beam Guard Fence; VicRoads: Melbourne, Australia, 2018.

54. Berndt, M.; Sanjayan, J.; Foster, S.; Castel, A.; Rajeev, P.; Heidrich, C. Progress Towards a Handbook for Geopolymer Concrete'. In Proceedings of the 27th Biennial National Conference of the Concrete Institute of Australia (Concrete 2015), Melbourne, Australia, 31 August-2 September 2015.

55. The Zeobond Group. Projects: Templestowe. Available online: http://www.zeobond.com/projects-templestowe.html (accessed on 4 March 2021). 